\title{
Confirmatory Factor Analysis of Learning Environment Instrument among High Performance School Students
}

\author{
Siti Mistima Maat ${ }^{1}$, Mazlini Adnan'2, Mohd Faizal Nizam Lee Abdullah², \\ Che Nidzam Che Ahmad', Marzita Puteh ${ }^{2}$ \\ ${ }^{1}$ Department Teaching and Learning Innovation, Faculty of Education, National University of Malaysia, \\ Bangi, Malaysia \\ ${ }^{2}$ Universiti Pendidikan Sultan Idris, Tanjung Malim, Malaysia \\ Email: sitimistima@ukm.edu.my, mazlini@fsmt.upsi.edu.my
}

Received 7 March 2015; accepted 27 April 2015; published 30 April 2015

Copyright (C) 2015 by authors and Scientific Research Publishing Inc.

This work is licensed under the Creative Commons Attribution International License (CC BY). http://creativecommons.org/licenses/by/4.0/

(c) (i) Open Access

\begin{abstract}
A learning environment has become one of the vital factors in ensuring the students' success in achieving good grades. Although past research focus on students' performance but the evolution of the learning environment has opened a new direction in understanding students' learning. There are many factors that can be grouped into the learning environment. This paper aims at validating the Learning Environment Instrument by using Confirmatory Factor Analysis (CFA) which has 40 items and 5-point Likert scale. The instrument has five constructs, including students' closeness, teacher support, involvement, cooperation and equality. The instrument was distributed to 1887 secondary school students from selected high performance school in Malaysia. Confirmatory Factor Analysis was used to validate the instrument using AMOS 16.0. The result revealed that the measurement model of learning environment fitted with the collected data. Fit index tests like CMIN/DF, TLI, CFI, IFI, NFI and RMSEA were used to obtain the model fit. In conclusion, the instrument was found to be valid and reliable in measuring learning environment in this context of study.
\end{abstract}

\section{Keywords}

Learning Environment, Confirmatory Factor Analysis, Mathematics, Students

\section{Introduction}

By general convention, learning environment refers to physical setting or virtual space where learning takes place. Conducive learning environment would be students' preferable factor since it helps them to learn better.

How to cite this paper: Maat, S. M., Adnan, M., Abdullah, M. F. N. L., Ahmad, C. N. C., \& Puteh, M. (2015). Confirmatory Factor Analysis of Learning Environment Instrument among High Performance School Students. Creative Education, 6, 640-646. http://dx.doi.org/10.4236/ce.2015.66063 
In order to achieve the Malaysian Vision of 2020 by having more skilled people, learning environment in academic institutions has to be a place for learner to engage in any kinds of learning activities (Partnership for 21st Century Skills, 2002). Learning environment is considered to be a quality of teaching from educators' perspective (Biggs, 1999). The relevancy of the learning environment is to improve students' learning outcome (Husain et al., 2014). Likewise, students can be influenced their learning environment. This defines the reciprocal interaction concept among humans that has been introduced by Bandura (1977) through his social learning theory. Students are found to have problem in familiarization of their learning environment especially in terms of classroom activities. The learning environment should give teachers the idea on how to organize their teaching and learning process. Improvement can be made based on the feedback and evaluation towards learning environment (Çakir, 2011).

Several important aspects in learning environment, including students' closeness, teacher support, involvement, cooperation and equality, have been measured quantitatively using What Is Happening in This Class (WIHIC) by Fraser and colleagues (1995). Gaps in teacher-student relationship are revealed when there exist unmatched mapping between teacher's expectation and students' achievement (Davis et al., 2011). Students are at risk when teachers do not offer warm-demanding approach. The approach will increase students' motivation and achievement especially when involvement is applied in the learning environment (Hunt, 2003). Through cooperation, the learning environment can be an interesting place to gain knowledge. However, students will not be able to perform if they are disconnected from teachers' attention (Brackett et al., 2011) and there is a tendency to be a failure. Furthermore, biasness among students will lead to poor attention during classroom process. Therefore, having a valid measurement on learning environment is one of the justifications in conducting this research.

Numerous researches on learning environment have been done, including Fraser (1998), Fraser and Walberg (1991) and Margianti et al. (2001). And there are different types of instruments in measuring learning environment including Classroom Environment Scale (Moos, 1979), College and University Classroom Environment Inventory (Fraser \& Treagust, 1986), Constructivist Learning Environment Scale (Taylor, Fraser, \& Fisher, 1997) and the latest one What is Happening in This Class? Questionnaire (Fraser, Giddings, \& McRobbie, 1995). The requirement of improving instruction and learning is through the evaluation of learning environment (Hofstein, Nahum, \& Shore, 2001). Good classroom climate will enhance students' attention and their interest in learning can be developed.

The research is extended to the evaluation of the psychometric purposes of the related measure of learning environment using Confirmatory Factor Analysis (CFA). Using CFA, it provides a validation aspect of constructs, especially in producing good reliability value (Harrington, 2009). Validation of the learning environment instrument is widely used nowadays among researchers including Çakmak et al. (2014), Fryer et al. (2011) and Çakir (2011). Therefore, the justification of conducting this research is to develop a concrete measure of learning environment specifically among students in Malaysian education setting. Furthermore, less focus is given to the study of learning environment and its relationship with students' achievement (Fraser, 2002). Thus, the research objective is to validate the learning environment using CFA for students of high school performance.

\section{Methodology}

A total of 1887 of secondary students from high performing school students were randomly selected to be involved in this study. High performance school in Malaysia has been implemented since January 2010. 100 schools were selected to be in the said category which can be defined to be excellent in producing holistic students as well as competent at international level. The said schools can be role model especially in enhancing the education quality to other schools.

The students are of 1107 (58.7\%) were female and 780 (41.3\%) were males. There were 1781 (94.4\%) Malays, 56 (3\%) Chinese, 41 (2.2\%) Indians and the remaining were other races. They were randomly chosen as the samples for this study. Letter of consent was obtained from the ministry for the researchers to conduct the research at these schools. The questionnaire was based on What Is Happening in This Class (WIHIC) (Fraser et al., 1995) which has a total of 40 items. There are five constructs, including students' closeness (8 items), teacher support (8 items), involvement (8 items), cooperation (8 items) and equality (8 items). All items were rated on a 5-point Likert scale which ranging from"1" as "Strongly Disagree" to "5" to "Strongly Agree”. Based on the reliability analysis, the Cronbach alpa value of the questionnaire is 0.960 which is at acceptable level (Hair et al., 2010). Likewise, each construct of learning environment has Cronbach alpha value ranging from 0.888 to 0.940 . These values are acceptable according to classification by Babbie (1992). This indicates that the reliability of all 
constructs of learning environment is consistent. Table 1 shows the detail of the reliability value for all the constructs.

\section{Results}

One suggested method of validating questionnaire is by using Confirmatory Factor Analysis (CFA). CFA can be used in scale development, testing the appropriateness of measures and to examine the use of measure in a model (Harrington, 2010). Using AMOS 16.0, the data were analyzed by validating a measurement model of learning environment through CFA. The covariance between latent variables is shown by a double headed arrow. The parameter estimation is based on the standardized output of CFA (Hashim \& Sani, 2008). The exploratory factor analysis is not conducted since the WIHIC questionnaire has been tested in the previous study. It has been validated by several researchers, including Dorman (2003), Clayton (2007) and Brok et al. (2005).

The hypothesized model of the learning environment is presented in Figure 1 with five latent constructs

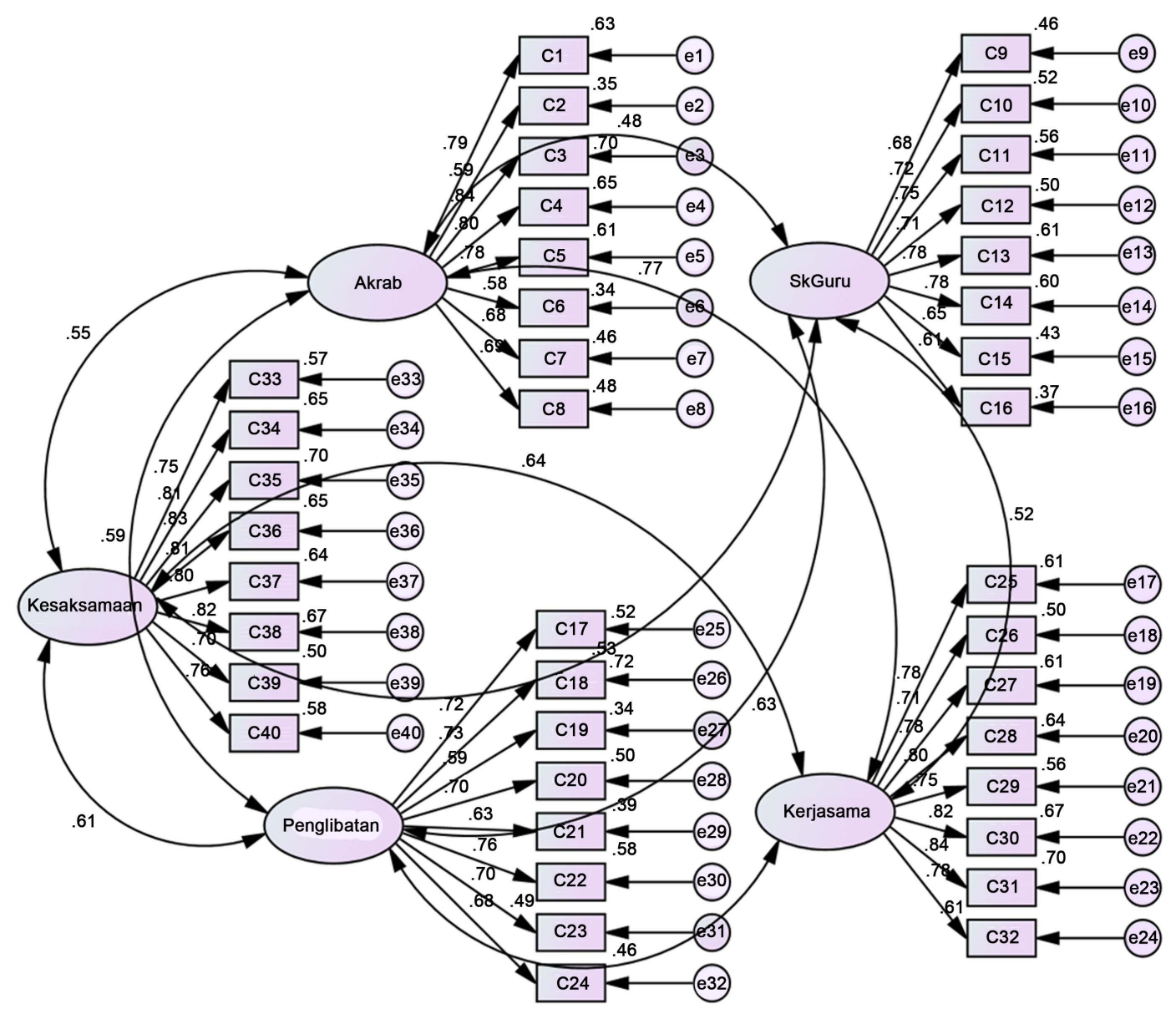

Figure 1. The hypothesized model of learning environment.

Table 1. Reliability value of learning environment constructs.

\begin{tabular}{cc}
\hline Construct & Cronbach Alpha \\
\hline Students' closeness & 0.894 \\
Teachers' support & 0.888 \\
Involvement & 0.876 \\
Cooperation & 0.925 \\
Equality & 0.940 \\
\hline
\end{tabular}


which represent students' closeness, teacher support, involvement, cooperation and equality respectively. The labeled for each latent construct is labeled as follows: students" closeness = "Akrab", teacher support = "SkGuru", involvement = "Penglibatan", cooperation = "Kerjasama" and equality = "Kesaksamaan". Each construct has 8 items of observed variables. Each observed variable has one measurement error which is indicated by a circle. Some fit index tests, like the relative chi-square (CMINDF: the chi-square/degree of freedom), Tucker Lewis Index (TLI), Comparative Fit Index (CFI), Incremental Fit Index (IFI), Normed Fit Index (NFI) and Root Mean Square of Error Approximation (RMSEA), are chosen in assessing model fit. The suggested acceptable value for relative chi-square, CMIN/DF should be as high as 5 which are used to reduce dependency on sample size. However, the cut-off point for TLI, CFI, NFI and IFI is between zero to one. A good model is indicated by RMSEA value of less than or equal to 0.05 (Schumacker \& Lomax, 2004).

Figure 2 shows the finalized measurement model of Learning Environment after considering all statistical fit index tests and modification index. The priority of maintaining the items in the model is given to items with factor loading more than 0.50 . The suggested cut-off point of 0.5 and above for each factor loading is based on Awang (2014). This value is applicable in order to achieve unidimensionality of a measurement model. Item with low loading factor loading should be deleted prior to the estimation of the new measurement model.

The initial finding shows that the chosen fit index test like TLI and NFI are still less than 0.9 as set by the requirement. However, the values of CMIN/DF, CFI, IFI and RMSEA have achieved the minimum cut-off point as shown in Table 2.

Modification index has to be considered in order to obtain the required value for fit index test of TLI and NFI. To increase these fit index values then item of C33 and C34 have to be deleted in order to reduce the discrepancy value by 98.757 . Creating covariances between e25 and e26 as well as e33 and e34 have increased the NFI value to 0.904 as shown in Table 3 .

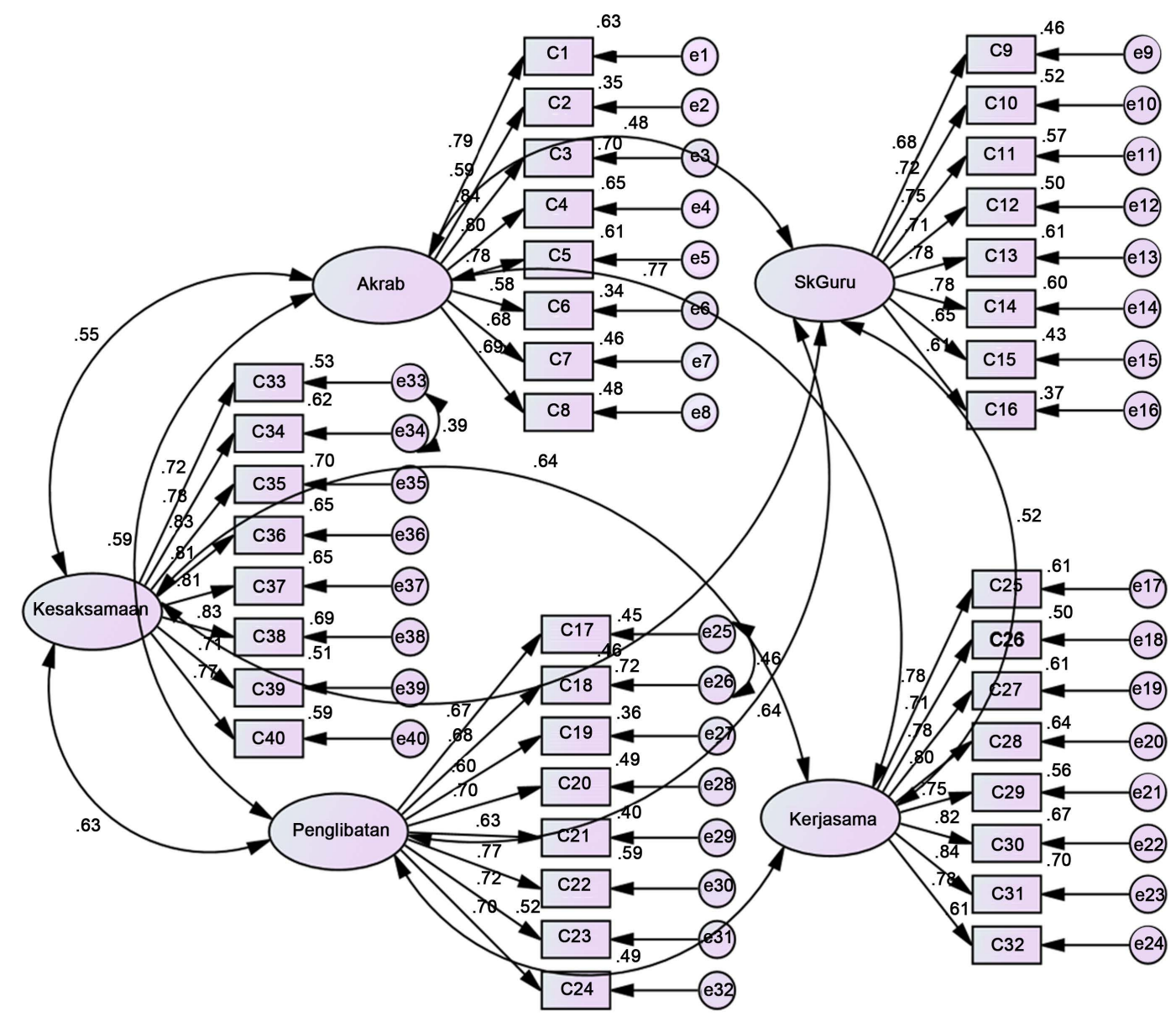

Figure 2. The finalized hypothesized model of learning environment. 
Table 2. The initial CFA of learning measurement model.

\begin{tabular}{ccccccc}
\hline Fit Index & CMIN/DF & TLI & CFI & IFI & NFI & RMSEA \\
Value & 6.900 & 0.904 & 0.911 & 0.911 & 0.897 & 0.056 \\
\hline
\end{tabular}

Table 3. The finalized CFA of learning environment measurement model.

\begin{tabular}{ccccccc}
\hline Fit Statistics & CMIN/DF & TLI & CFI & IFI & NFI & RMSEA \\
\hline Value & 6.413 & 0.912 & 0.918 & 0.918 & 0.904 & 0.054 \\
\hline
\end{tabular}

The strength of each relationship between the latent variables is given by the correlation value that is established on every two head arrow. The t-test is used to measure the significant of the said relationship. All correlation values are significant and moderate strength which ranging from $r=0.52$ to $r=0.63$.

By performing the CFA again, it is found that all the fit statistics index has fulfilled the requirement condition. The relative chi-square is at an acceptable range of 6.413, the other fit statistics like TLI $=0.912$, CFI $=0.918$, IFI $=0.918$ and NFI $=0.904$ are more than the cut-off value of 0.90 . While the RMSEA $=0.05$ is much better than the suggested value of 0.08 . All values of the fit statistics are shown in Table 3. As a conclusion, the collected data is fit with the measurement model of learning environment based on CFA.

\section{Discussion}

The analysis has yielded five factors of learning environment including students' closeness, teacher support, involvement, cooperation and equality. Two items have to be deleted and two covariances are created as suggested by the modification index. Goodness of fit indices of CFA indicated a good fit of the collected data and the model. The correlation values of the respective relationship in the model are better than the values which have been obtained by Dorman (2003). This indicates that the learning environment questionnaire is acceptable in measuring all the five constructs of learning environment which is based on the requirement (Hair et al., 2010). Although the learning environment instrument has been tested in the previous studies, conducting CFA will ensure the validity of the instrument.

The use of CFA is also to assess the learning environment questionnaire in different research settings so that the empirical evidence can be enhanced. Having relevant dimensions of learning environment questionnaire, it provides a comprehensive measurement of the chosen constructs (Brok et al., 2005). It quantifies the learning environment created by the educational institution. In addition, comfortable learning environment would enhance students' achievement (Waldrip \& Fisher, 2003).

Some limitations of the present study include the use of cross-sectional data to determine the relationship among all constructs only without considering the causal directional relationship. This is due to demanding criteria when using structural equation modeling (Tracz, 1992).

\section{Conclusion}

The output of CFA has become the evidence of reliability and the validity of the Learning Environment in this context of study especially among high performance school students. With this validated questionnaire, the future research of learning environment will get benefit from the psychometric aspect. The questionnaire is applicable to measure learning environment that has been supported widely by many studies. The present study can be extended to different settings and samples in order to achieve a better measurement model. It is hoped that by validating the learning environment instrument, more upcoming related issues will be conducted in the future in order to facilitate students' learning. However, by considering triangulation in the current methodology, it gives more support in terms of measurement and evaluation of the instrument.

This study is vital in Malaysian mathematics education since the scope of the learning environment has changed which align with the technology development. A thorough investigation on the real classroom setting can be done so that more inputs can be obtained for the betterment of the future education.

\section{Acknowledgements}

We extend our gratitude to Ministry of Education of Malaysia for awarding Research Acculturation Grant 
Scheme (RAGS) financial support in the implementation of this research. Special thanks to the selected High Performance School in Malaysia and Universiti Pendidikan Sultan Idris for the involvement in this research.

\section{References}

Awang, Z. (2014). Research Methodology and Data Analysis (2nd ed.). Universiti Teknologi Mara, UiTM Press.

Babbie, E. (1992). The Practice of Social Research. Belmont, CA: Wadsworth Publishing Company.

Bandura, A. (1977). Social Learning Theory. Englewood Cliffs, NJ: Prentice-Hall.

Biggs, J. (1999). Teaching for Quality Learning at University. Birmingham: The Society for Research into Higher Education and Open University.

Brackett, M. A., Reyes, M. R., Rivers, S. E., Elbertson, N. A., \& Salovey, P. (2011). Classroom Emotional Climate, Teacher Affiliation, and Student Conduct. Journal of Classroom Interaction, 46, 27-36

Brok, P. D., Fisher, D., Rickards, T., \& Bull, E. (2006). Californian Science Students’ Perception of Their Classroom Learning Environment. Educational Research and Evaluation, 12, 3-25. http://dx.doi.org/10.1080/13803610500392053

Çakir, M. (2011). Validity and Reliability of the Turkish Form of Technology-Rich Outcome-Focused Learning Environment Inventory. Educational Sciences: Theory\& Practice, 11, 1959-1963.

Çakmak, E. K., Çebi, A., \& Kan, A. (2014). Developing a "Social Presence Scale” for E-learning Environments. Educational Sciences Theory and Practice, 14, 764-768.

Clayton, J. (2007). The Validation of the Online Learning Environment Survey. Proceedings Ascilite Singapore 2007, 2-5 December 2007, Singapore, 159-167.

Davis, H. A., Gabelman, M. M., \& Wingfield, R. D. (2011). “She Let Us Be Smart:” Low-Income African-American First-Grade Students' Understandings of Teacher Closeness and Influence. The Journal of Classroom Interaction, 46, 4-6.

Dorman, J. P. (2003). Cross-National Validation of the What Is Happening in This Class? (WIHIC) Questionnaire Using Confirmatory Factor Analysis. Learning Environments Research, 6, 231-245. http://dx.doi.org/10.1023/A:1027355123577

Fraser, B. J. (1998). Classroom Environment Instruments: Development, Validity and Applications. Journal of Learning Environment Research, 1, 7-34. http://dx.doi.org/10.1023/A:1009932514731

Fraser, B. J. (2002). Learning Environments Research: Yesterday, Today, and Tomorrow. In S. C. Goh, \& B. Kahle (Eds.), Studies in Educational Learning Environments (pp. 49-72). Singapore: World Scientific Publishing.

Fraser, B. J., \& Treagust, D. F. (1986). Validity and Use of an Instrument for Assessing Classroom Psychosocial Environment in Higher Education. Higher Education, 15, 37-57. http://dx.doi.org/10.1007/BF00138091

Fraser, B. J., \& Walberg, H. J. (1991). Education Environment: Evaluation, Antecedents and Consequences. Oxford: Pergamon Press.

Fraser, B. J., Giddings, G. J., \& McRobbie, C. J. (1995). Evolution and Validation of Personal Form of an Instrument for Assessing Science Laboratory Classroom Environments. Journal of Research in Science Teaching, 32, 399-422. http://dx.doi.org/10.1002/tea.3660320408

Fryer, L. K., Ginns, P., Walker, R. A., \& Nakao, K. (2011). The Adaptation and Validation of the CEQ and the R-SPQ-2F to the Japanese Tertiary Environment. British Journal of Educational Psychology, 82, 549-563.

Hair, J. F., Anderson, R. E., Tatham, R. L., \& Black, W. C. (2010). Multivariate Data Analysis (7th ed.). Englewood Cliff, NJ: Prentice Hall.

Harrington, D. (2009). Confirmatory Factor Analysis. New York: Oxford University Press.

Hashim, R. A., \& Sani, A. M. (2008). A Confirmatory Factor Analysis of Newly Integrated Multidimensional School Engagement Scale. MJLI, 5, 21-40.

Hofstein, A., Nahum, T. L., \& Shore, R. (2001). Assessment of Learning Environment of Inquiry-Type Laboratories in High School Chemistry. Learning Environments Research, 4, 193-207. http://dx.doi.org/10.1023/A:1012467417645

Hunt, S. K. (2003). Encouraging Student Involvement: An Approach to Teaching Communication. Communication Studies, 54, 133-136. http://dx.doi.org/10.1080/10510970309363275

Husain, M. Y., Mustapha, R., Malik, S. A., \& Mokhtar, S. B. (2014). Review of Measurement Item of Engineering Student’s Learning Environment: Confirmatory Factor Analysis. Journal of Technical Education and Training, 6, 42-56.

Margianti, E. S., Fraser, B. J., \& Aldridge, J. M. (2001). Investigating the Learning Environment and Students' Outcomes in University Level Indonesia. Work paper Presented at Annual Conference of American Educational Research Association, Seattle, 10-14 April 2001.

Moos, R. H. (1979). Evaluating Educational Environments: Procedures, Measures, Findings and Policy Implications. San Francisco, CA: Jossey-Bass. 
Partnership for 21st Century Skills (2002).

Schumacker, R. E., \& Lomax, R. G. (2004). A Beginner's Guide to Structural Equation Modeling. Mahwah, NJ: Lawrence Erlbaum Associates.

Taylor, P. C., Fraser, B. J., \& Fisher, D. L. (1997). Monitoring Constructivist Classroom Learning Environments. International Journal of Educational Research, 27, 293-302. http://dx.doi.org/10.1016/S0883-0355(97)90011-2

Tracz, S. M. (1992). The Interpretation of Beta Weights in Path Analysis. Multiple Linear Regression Viewpoints, 19 , 7-15.

Waldrip, B., \& Fisher, D. (2003). Identifying Exemplary Science Teachers through Their Classroom. Learning Environments Research, 6, 157-174. 